\title{
A propósito del problema del espacio en Hegel
}

SANTiago Vera

Pontificia Universidad Católica del Perú

Resumen: El artículo busca rastrear el lugar que ocupa el concepto de espacio en la filosofía de Hegel, pero tomando como hilo conductor la interrogante por la necesidad de su subordinación en relación al concepto de tiempo en el marco de la teleología hegeliana de la historia. En un primer momento, plantearemos el problema de la relación entre el espacio (natural) y el tiempo (natural-espiritual), ubicando cada término en su lugar sistemático correspondiente. En un segundo momento, ilustramos la operatividad del problema a lo largo de tres escenarios: el lenguaje, el arte y la geografía. En el marco de una investigación más amplia acerca de la devaluación que históricamente ha sufrido el espacio respecto de la preminencia categorial del tiempo, este trabajo busca identificar en la filosofía de Hegel una dentro de varias estrategias conceptuales posibles con que se legitima dicha preminencia.

Palabras claves: espacio, historia, lenguaje, arte, geografía.

Abstract: The paper aims to locate the concept of space within Hegel's philosophy, interrogating the necessity of its subordination in relation to the concept of time within the framework of the Hegelian teleology of history. The first part considers the problem of the relation between (natural) space and (natural-spiritual) time, placing each concept in its corresponding systematic location. The second part illustrates how this problem operates within three scenarios: language, art and geography. In the context of a wider research regarding the historical devaluation that space suffered in relation to the categorical preeminence of time, this paper intends to identify one among many conceptual strategies whereby this preeminence acquires legitimation in Hegel's philosophy.

Keywords: space, history, language, art, geography. 


\section{§ 1. Introducción}

El presente artículo trata sobre un aspecto del concepto de espacio tal como es desarrollado en la filosofía de Hegel, pero los análisis que en él se esbozan persiguen la intención de contribuir a generar una reflexión más amplia acerca del lugar relegado que ha ocupado históricamente en la filosofía, y en las ciencias humanas y sociales en general, el pensamiento del espacio respecto del protagonismo categorial del tiempo'. Dado que este es un problema que requiere de un marco conceptual sólido que permita explorarlo con eficacia, quizá un buen punto de partida para ello sea atender al modo en que opera el problema mencionado en la filosofía hegeliana, precisamente aquella para la cual la reflexión acerca del tiempo y de la historia representó una de las tareas que nuestro pensador asumió con mayor urgencia. Este trabajo pretende ser ese punto de partida y la motivación de fondo de las interrogantes que lo animan apuntan a la dirección señalada. ¿Cómo piensa, pues, Hegel el espacio en relación con el tiempo en el marco de su concepción teleológica de la historia? ¿Cuáles son las condiciones de inteligibilidad del espacio considerando su anclaje en la exterioridad de la naturaleza? ¿Hasta qué punto es posible, en ese sentido, interpretar los mecanismos dialécticos de producción espiritual echando mano de categorías propias del estadio de la naturaleza?

Tratándose de preguntas difíciles de desarrollar en el marco reducido de un artículo, preferimos pensar que la pretensión de este se limita tanto a trazar algunas pistas útiles para abordarlas, como a sugerir el valor y el interés de su planteamiento. Para ello se empezará contrastando un conjunto de pasajes

I La literatura es abundante al respecto, dando lugar a lo que algunos autores han llamado un "giro espacial" operante en las ciencias humanas y sociales desde aproximadamente mediados del siglo XX y caracterizado por un creciente interés por las categorías espaciales para el estudio de la sociedad y la cultura (cf. Jameson, Frederic, Postmodernism, or the cultural logic of capitalism, London: Verso, 199I, p. 154). La siguiente cita de Foucault es ilustrativa al respecto: "La gran obsesión que tuvo el siglo XIX fue, como se sabe, la historia: temas del desarrollo y de la interrupción, temas de la crisis y del ciclo, temas de la acumulación del pasado, gran sobrecarga de los muertos, enfriamiento amenazante del mundo. En el segundo principio de la termodinámica el siglo XIX encontró lo esencial de sus recursos mitológicos. La época actual quizá sea sobre todo la época del espacio. Estamos en la época de lo simultáneo, estamos en la época de la yuxtaposición, en la época de lo próximo y lo lejano, de lo uno al lado de lo otro, de lo disperso. Estamos en un momento en que el mundo se experimenta, creo, menos como una gran vida que se desarrolla a través del tiempo que como una red que une puntos y se entreteje" (Foucault, Michel, “Los espacios otros”, en: Architecture, Mouvement, Continuité, No. 5, Octubre (1984), pp. 45-49. Traducción al español por Luis Gayo Pérez Bueno). 
de la obra de Hegel con el fin de intentar orientarnos en sus respectivas tensiones. Esta primera aproximación busca enmarcar el lugar del espacio y el tiempo dentro del sistema expuesto en la Enciclopedia, a la vez que plantea el problema cuyo rastro guiará el curso de esta investigación. Una vez delineada la ruta, en un segundo momento, se explorará su operatividad en el marco de tres escenarios inscritos al interior de la filosofía del espíritu: el lenguaje, el arte y la constitución geográfica de los pueblos. Se trata de momentos cuya articulación conceptual por el momento dejaremos de lado, interesándonos más bien en la compleja relación que en ellos opera de modo análogo entre el espacio natural, por un lado, y la escisión del tiempo como naturaleza yespíritu, por el otro, así como la eficacia sistemática de dicha escisión. De esta forma, el hilo que guiará nuestra exposición oscila entre la filosofía de la naturaleza y la filosofía del espíritu, y busca aprovechar dicho movimiento a fin de analizar las estrategias de producción espiritual que la dialéctica pone en marcha.

\section{§ 2. Planteamiento del problema}

Dentro de su prolífica obra, uno de los enunciados en que Hegel condensara con mayor eficacia la naturaleza dialéctica de la historia, lo encontramos en sus lecciones de 1830 editadas por $\mathrm{G}$. Lasson bajo el título de Lecciones sobre la filosofía de la historia universal. En esta obra Hegel afirma: "Lo natural y lo espiritual forman un conjunto vivo, que es la historia"2. Advertimos el carácter dialéctico que dicha formulación comporta al atender a la definición que sobre la naturaleza ofrece la Enciclopedia y que la coloca precisamente como la instancia en que uno de los términos de la ecuación, la idea o espíritu, se manifiesta en su forma exterior o su ser otro: "La naturaleza ha resultado como la idea en la forma del ser-otro (...) la exterioridad constituye la determinación en que la idea está como naturaleza"3. En tanto que síntesis de lo espiritual y lo natural, la historia universal representaría, en consecuencia, "el elemento en que existe el espíritu universal (...) en toda la extensión de su interioridad y

2 Hegel, G.W.F., Lecciones sobre la filosofía de la historia universal, traducción de José Gaos, Madrid: Alianza Editorial, 2008, p 195. En adelante LFHU.

3 Hegel, G.W.F., Enciclopedia de las ciencias filosóficas, traducción de Ramón Valls Plana, Madrid: Alianza Editorial, 2005, § 247. En adelante Enc. 
de su exterioridad" y el devenir de su marcha describiría la unidad negativa, dialéctica, de ambas instancias.

Ahora bien, en un nivel bien elemental, decir que la historia representa la manifestación de la interioridad del espíritu en la exterioridad de la naturaleza es decir que, en tanto historia, el espíritu aparece al interior de un espacio y un tiempo. Sin embargo, así planteado el asunto es difícil advertir la complejidad que supone dicha afirmación. En realidad, ella sola trae consigo una serie de problemas que exigen un esfuerzo interpretativo que no le rehúya a ese rasgo tan propio del sistema hegeliano, donde el dinamismo y el carácter oscilante de los conceptos exigen una atención especial, y uno de cuyos aspectos es, a grandes rasgos, el que expondré a continuación.

Por un lado, la exposición sobre el espacio y el tiempo aparece al interior de la filosofía de la naturaleza, momento en que, como señalamos, el espíritu se encuentra como algo exterior a sí. Espacio y tiempo son, en efecto, las primeras determinaciones de la Mecánica, que es a su vez el primer y por tanto más abstracto estadio de la Naturaleza ${ }^{5}$. En la Enciclopedia la definición de ambos reza: "El uno-fuera-de-otro enteramente abstracto", las "formas puras de la sensibilidad o el intuir (son ambos) lo sensible-no sensible"7. Desde este nivel, espacio y tiempo aparecen por igual, sin que se evidencie aún una discontinuidad categorial entre los mismos, como las formas exteriores en que el espíritu se realiza al relacionarse activamente consigo mismo en lo otro y cuyo proceso dialéctico, veíamos, no es otro que el devenir de la historia universal.

Pero por otro lado, ya el sentido común indica una primera dificultad: no puede significar lo mismo decir que la historia se manifiesta en el espacio a decir que la historia se manifiesta en el tiempo. Y, en efecto, existe una buena cantidad de pasajes dentro del corpus hegeliano orientados a desarrollar esa diferencia. Me interesa destacar dos: uno a) relativo a la filosofía de la naturaleza, el otro b) inscrito en la filosofía del espíritu. Un breve examen de ambos pasajes serviría de entrada para profundizar en las condiciones sistemáticas que posibilitan

4 Hegel, G.W.F., Principios de la filosofía del derecho o derecho natural y ciencia política, traducción de Juan Luis Vermal, Buenos Aires: Editorial Sudamericana, 1975, § 331.

5 Hegel, G.W.F., Enc, § 253.

6 Ibid.

967 lbid., § 258. 
dicha diferencia, así como en la operatividad de la misma y su importancia dentro del marco hegeliano de una filosofía de la historia.

a) Una primera discontinuidad categorial entre el espacio y el tiempo la encontramos en la misma sección de la Mecánica citada anteriormente. Ya de entrada el que la exposición del espacio preceda a la exposición sobre el tiempo no puede en la filosofía hegeliana, donde el método y el contenido de la exposición mantienen una relación orgánica, pasar inadvertida. En efecto, Hegel afirma que "la primera o inmediata determinación de la naturaleza es la abstracta universalidad de su ser afuera de sí, cuya indiferencia carente de mediación es el espacio. Este es el uno-junto-a-otro enteramente ideal (...) porque ese uno-fuera-del-otro es todavía enteramente abstracto y no tiene en él ninguna diferencia determinada" ${ }^{8}$. Es, por tanto, el espacio, antes que el tiempo, la instancia en que la naturaleza alcanza su primera y más abstracta exterioridad.

La razón de esta anterioridad del espacio respecto del tiempo como determinación de la naturaleza se esclarece al atender a la lógica de acuerdo a la cual se articula el transito del espacio al tiempo tal como es expuesto en la Enciclopedia: "La negatividad que, como punto se refiere al espacio (...) en la esfera del ser-afuera-de-sí es también ciertamente para sí juntamente con sus determinaciones, pero a la vez, siendo ponente en esta esfera del ser afuera de sí, la negatividad está apareciendo como indiferente ante el quieto uno-junto-a-otro. Puesta de este modo para sí, la negatividad es el tiempo"’.

Si bien en el marco de una lectura crítica en la que no nos detendremos, Heidegger ha profundizado en el análisis de este complicado pasaje en uno de los últimos apartados de Ser y tiempo. Según el autor, este pasaje deja claro que para Hegel la realidad del tiempo como verdad o superación (Aufhebung) del espacio pasa por pensarlo como una "negación de la negación"।0. Una primera negación del espacio, pero también su condición de determinación como tiempo, lo constituye el punto. Como exterioridad inmediata el espacio

\footnotetext{
$8 \quad$ lbid., $§ 254$.

$9 \quad$ lbid., § 257.

10 Heidegger, Martin, El ser y el tiempo, traducción de José Gaos, México D.F.: Fondo de Cultura Económica, 1983, p. 465.
} 
es puntualidad, es decir, una multiplicidad abstracta e indiferenciada de puntos en simple relación de coexistencia. Pero si, por un lado, la puntualidad constituye el espacio, por el otro, lo niega, pues todo punto es un punto-aquí, es decir, la realidad de la diferencia y el límite, realidad que posibilita a su vez la aparición de las dimensiones espaciales ulteriores, como lo son la línea y la superficie. Pues bien, el repliegue del "uno-junto-a-otro" espacial al punto, obliga a pensar al espacio como ahora, de tal forma que lo que en el espacio aparecía como simultaneidad de aquíes coexistentes, se traduce temporalmente como devenir o sucesión de ahoras, ahoras-antes y ahoras-después. De esta forma, esta, "negación de la negación o puntualidad (espacial) es, según Hegel, el tiempo"'l. Esta exposición tendría como propósito superar la representación común del espacio como algo separado y externo al tiempo. El tiempo negaría y recogería en sí la exterioridad inmediata e indiferenciada del espacio, realizando su propia verdad. El espacio es tiempo.

b) Quizá uno de los pasajes más decisivos en función a discernir el rol del tiempo en comparación al del espacio en la constitución de la historia lo hallamos en las Lecciones sobre la filosofía de la historia universal. Aquí leemos: "La historia universal es el desenvolvimiento, la explicitación del espíritu en el tiempo, del mismo modo que la idea se despliega en el espacio como naturaleza"'2. Este pasaje es crucial. Nos obliga a reordenar los términos del esquema hasta ahora expuesto y a distinguir al menos dos niveles al interior de los cuales el tiempo fluctúa. Si hasta el momento espacio y tiempo han sido definidos ambos como determinaciones de la naturaleza, aquí es el espacio el que queda relegado como mera determinación exterior de la naturaleza, mientras que el tiempo aparece como liberado de dicha exterioridad e incorporado a la interioridad del espíritu y a su manifestación como historia. Esto esclarecería la definición que desde el punto de vista de la filosofía de la naturaleza colocaba al tiempo como la superación (Aufhebung) o verdad del espacio. El tiempo sería el elemento comunicante, diríamos, homogéneo tanto a la naturaleza como al espíritu, a través del cual el espacio negocia un refugio en la interioridad del espíritu y un emplazamiento al interior de la sede de la historia. Y esto, evidentemente, plantea el problema de la existencia de dos niveles en que el 
concepto de tiempo quedaría escindido: tiempo espiritual o histórico, por un lado, y tiempo natural, por el otro.

El debate al respecto es, por supuesto, complejo. Heidegger, por ejemplo, ha insistido en la tesis según la cual aun cuando Hegel hable "del tiempo en el contexto de la problemática de la historia e incluso del espíritu, eso acontece siempre en una más lata transposición formal a esos ámbitos del concepto de tiempo procedente de la filosofía de la naturaleza"|3. Esto implicaría una comprensión espacial del tiempo (tiempo como caída...), que no es otra, a juicio de Heidegger, que la "comprensión vulgar del tiempo" y respecto de la cual el concepto hegeliano sería la "elaboración conceptual más radical"14. Del otro lado, en sus estudios sobre la Fenomenología del espíritu de Hegel, Alexandre Kojève se inclina por una interpretación contraria. Si bien reconoce "la existencia de un Tiempo cósmico [en nuestros términos, natural] y de un Tiempo histórico", afirma que Hegel termina por identificar ambos tiempos sin más, de tal forma que "podemos aplicar al Tiempo histórico (...) todo cuanto dice del Tiempo en general”'15.

Ninguna de las dos posiciones me parece del todo exacta. Al contrario de lo propuesto por ambos autores, una de las tesis que desarrollaré en lo que sigue es que si bien resulta más congruente con la posición sistemática de Hegel buscar su comprensión del tiempo en el movimiento de la historia, es decir, en el tiempo como determinación del espíritu ${ }^{16}$, resulta a la vez más

I3 El pasaje completo es el siguiente: "Debe ser destacado con todo vigor que espacio y tiempo son primariamente para Hegel, desde el inicio -y sigue siéndolo en la totalidad de su filosofía-, problemas de la filosofía de la naturaleza (...). Y si Hegel habla ahora del tiempo en el contexto de la problemática de la historia e incluso del espíritu, eso acontece siempre en una más lata transposición formal a esos ámbitos del concepto de tiempo procedente de la filosofía de la naturaleza. La problemática del tiempo, por el contrario, no es desplegada primariamente a partir del concepto de la historia e incluso del espíritu, y esto no es así por la sencilla razón de que ello iría contra la intención fundamental de Hegel como ninguna otra cosa podría hacerlo" (Heidegger, Martin, La fenomenología del espíritu de Hegel, Madrid: Alianza Editorial, 1992, p. 242).

14 Heidegger, Martin, El ser y el tiempo, p. 46I.

I5 Kojeve, Alexandre, Introducción a la lectura de Hegel, Madrid: Editorial Trotta, 2013, p. 419.

16 Para un desarrollo sistemático de esta tesis, en oposición a la lectura referida de Heidegger, cf. De la Maza, Luis Mariano, "La crítica de Heidegger al concepto hegeliano del tiempo en la Fenomenología del espíritu”, en: Lemm, Vanessa y Juan Ormeño (eds.), Hegel, pensador de la actualidad. Ensayos sobre la fenomenología del espíritu y otros textos, Santiago: Ediciones Universidad Diego Portales, 2009. 
interesante hacerse realmente cargo de la escisión del tiempo descrita, que lo sitúa de un lado como determinación de la exterioridad de la naturaleza, y del otro como determinación de la interioridad del espíritu y su devenir como historia. Habría que explorar en este sentido la operatividad de dicha escisión al interior del sistema, así como analizar críticamente en qué medida la necesidad de dicha escisión se sostiene sobre la base de una determinada concepción de la historia, según la cual, como es sabido, su trayecto describe un movimiento teleológico cuya consumación recoge e interioriza la totalidad de las diferencias de los momentos precedentes para reunirlas finalmente en un todo unitario y pleno.

Es claro en este contexto por qué dicha escisión del tiempo merece una atención especial, y cómo además en este marco el espacio adquiere una dimensión problemática. En relación a lo primero, advirtamos que tal escisión no tendría, en principio, por qué resultar sospechosa. De hecho, ya Aristóteles hablaba, por un lado, del tiempo como medida del movimiento, mientras que, por el otro, dicha medida no sería posible si no se contara a la propia temporalidad como una de las estructuras fundamentales de la psyché; $y$, Kant, de un tiempo que conforma el esquema de la imaginación, mediador entre las categorías del entendimiento y la intuición sensible. Sin embargo, y aquí lo crucial, desde el momento en que en la filosofía hegeliana dicha escisión opera dentro del marco más amplio de una filosofía de la historia, resultaría interesante preguntarse por la posibilidad de que la misma no funcione sino como, digamos, el recurso operativo del cual la historia echaría mano para gobernar el trayecto de su desarrollo. Así puestas las cosas, sería posible interpretar este movimiento como un recurso análogo al del famoso ardid o astucia de la razón. Me permito decirlo en términos gráficos: en su proceso de enajenación como naturaleza el espíritu no necesitaría, por decirlo así, exponerse al peligro, sino que le bastaría con infiltrar un aliado que disponga y prepare el terreno de su triunfo. ¿No será el tiempo esta suerte de "funcionario" del espíritu, infiltrado en la naturaleza con el objetivo de penetrar su alteridad y preparar con ello su camino de retorno a la interioridad espiritual?

Pues bien, ¿cómo se sitúa y cuál es el rol del espacio en el marco del esquema descrito? Una forma apresurada de plantearlo es decir que el espacio es la mera alteridad indistinta de la naturaleza, la diferencia por antonomasia, y es en ese sentido ininteligible, refractario al espíritu y, por tanto, a la historia. El 
asunto planteado a la luz del esquema anterior, sin embargo, corrige esa imprecisión y delinea la ruta que rastrearemos en adelante: que el tiempo sea la verdad del espacio y que, al mismo tiempo, funcione como aquella estructura fluctuante entre la exterioridad de la naturaleza y la interioridad del espíritu, significaría que el tiempo es, pues, (y permítaseme insistir en imágenes) esa instancia fundamental de enlace entre la "mudez" de la naturaleza espacial y la "elocuencia" del espíritu histórico, aquel elemento "traductor" a través de cuyo desenvolvimiento como historia el espacio adquiere inteligibilidad $y$, digamos, una dignidad suficiente para agenciarse un lugar al interior de su sede. Pues bien, es sobre la base de esta intuición que nos proponemos identificar en adelante tres escenarios de revocación espacial en los que operaría la estrategia descrita: el lenguaje, el arte y la constitución geográfica de los pueblos. La inteligibilidad de la naturaleza pasaría, en cada uno de estos escenarios, por someter a su espacio a procesos de temporalización gradual, resolviendo su exterioridad en la interioridad del espíritu e incorporándose en ese tránsito al dictum de la historia.

\section{§ 3. "Lo que hubiera querido decir el espacio, es el tiempo"17}

\subsection{Lenguaje y espacio}

Dentro de la teoría del signo lingüístico, expuesta como parte de una teoría de la imaginación entre los parágrafos $§ 446$ y $§ 464$ de la Enciclopedia, la escisión antes descrita del tiempo en su determinación natural y espiritual encuentra una operatividad correlativa. En tanto naturaleza el tiempo funciona, junto con el espacio, como la forma de la intuición sensible del que la inteligencia recoge la materia de sus ulteriores determinaciones sígnicas (producidas estas por medio de la fantasía o imaginación reproductora - reproducktive Einbildungskraft $)^{18}$. Por medio de la representación, esta materia es interiorizada y almacenada como imagen al interior de la inteligencia, conformando una especie de reserva o pozo del que ésta se servirá en adelante para enlazar libremente una intuición icónica cualquiera con un significado ajeno a

17 Derrida, Jaques, "El pozo y la pirámide", en: Hyppolite, Jean, Hegel y el pensamiento moderno, traducción de Ramón Salvat, México D.F.: Siglo Veintiuno, 1977, p. 60.

I8Cf. Hegel, G.W.F., Enc, § 448. 
su contenido inmediato. En este movimiento de enlace encontramos ya un primer momento de espiritualización operado por el tiempo ${ }^{19}$. Temporalizar significa, según esto, atribuirle al contenido intuitivo de la imagen un significado que como inmediatez no contiene.

Pero la preminencia categorial del tiempo sobre el espacio en el proceso de constitución del signo, destaca con mayor claridad si atendemos al tercer y último momento de espiritualización. Es este el estadio de la apariencia del signo. Pasamos de una primera intuición "muda" a otra que, habiendo pasado ya por el filtro de la inteligencia, retorna a su determinación natural (vuelve a ser cosa, apariencia sensible) pero de manera más determinada; una apariencia que ha devenido "elocuente". Así, si en la primera intuición, mera materia del signo, Hegel sitúa al espacio y el tiempo en niveles homogéneos ${ }^{20}$, la instancia de aparición más adecuada para esta nueva intuición espiritualizada debe ser la del tiempo y no la del espacio: "La intuición, que como inmediata es en primer lugar algo dado y espacial, en tanto se utiliza (haciéndola) un signo recibe la determinación esencial de ser solamente en tanto superada (...); así, la figura más verdadera de la intuición que es un signo es una existencia en el tiempo"21.

Se constata por lo pronto que el movimiento del signo describe la superación de la intuición espacial: el signo es un cierto espacio devenido tiempo. Propongo interpretar esta supremacía temporal a la luz de la formulación arriba descrita que presenta al tiempo escindido como naturaleza y espíritu, y al espacio desplazado exclusivamente a la naturaleza. Esta escisión, como vimos, esclarece su sentido en la definición que sobre el tiempo ofrece la Enciclopedia: el tiempo es la superación (Aufhebung) del espacio. Para empezar, que el signo se haya mostrado como un espacio devenido tiempo quiere decir, en un nivel bien elemental, que solo en el tiempo el espacio significa. Pero repasemos ahora qué implica este movimiento del significado habiendo situado a sus dos términos, espacio y tiempo, en su lugar sistemático correspondiente. Si el lugar del espacio es exclusivamente la naturaleza y solo el tiempo posee la cualidad de ser espiritual y natural a la vez, diríamos que el

\section{Cf. ibid., § 455.}

20 "La inteligencia determina así el contenido de la sensación como un ente fuera de ella, lo arroja fuera en el espacio y en el tiempo que son las formas en las cuales la inteligencia es intuitiva" (ibid., § 448). 
significado representa el movimiento de absorción de la naturaleza por parte del espíritu a través de aquel principio mediador y, por tanto, homogéneo a ambos: sensible e inteligible, externo e interno, natural y espiritual: el tiempo 22 . El tiempo, así, sería esa especie de liberador del estrés de una inmanencia espacial incapaz de significar como tal. Traduce la voluntad significante pero muda del espacio decodificando su inmediatez en términos espiritualmente inteligibles. Hace, pues, de la naturaleza, signo. Absuelve la "impotencia de la naturaleza" ${ }^{23}$ restituyendo su verdad en la superación aplazada de sí misma. Derrida lo dice bien: "Lo que hubiera querido decir el espacio, es el tiempo" 24 .

Pero ahondemos un poco más en qué significa el que el tiempo sea la forma esencial de la apariencia del signo. Esto nos conduce a interrogar cuál es el tipo de configuración sensible que le corresponde a esta cosa-signo en tanto ha operado ya en ella el movimiento de espiritualización (significado).

Tratándose de una cosa sensible espiritualizada, el signo habrá de estar constituido por una materia tal que se sitúe a medio camino entre la sensibilidad de la naturaleza y la idealidad del espíritu. Esta ambivalencia es propia de lo que Hegel llama las “idealidades físicas”: la luz y el sonido ${ }^{25}$. La luz es en cierto sentido ideal porque no trastoca ni altera a las cosas que ilumina, sino que las hace aparecer a la vista tal y como se nos manifiestan. Pero el sonido es más ideal que la luz, pues no solo no altera a los objetos para captarlos, sino que además trasciende su mera imagen extensa para penetrar en ellos y absorber esa suerte de "intima vibración" o "temblor" de su presencia. El sonido, se

22 Josef Simon ha hecho ver cómo, siendo el tiempo el que en virtud de su ambivalencia natural-espiritual constituye el eje fundamental que atraviesa toda la teoría del signo hegeliana, interrogarnos sobre la relación tiempo-signo lingüístico supone abordar la relación entre lo sensible e inteligible en toda su complejidad, lo cual alumbraría problemas de un carácter epistemológico más amplio: "iHasta qué punto es posible, (...), experimentar la unidad de estar consigo o en sí y estar al mismo tiempo fuera de sí (...). ¿ iHasta qué punto la actividad del yo mismo actúa y es también constitutiva en la intuición de objetos (...)?” ¿Cómo abordar, pues, "la pregunta por la superación y simultánea constitución de la trascendencia, esto es, por el esquema que media entre unidad y disgregación y que en consecuencia constituye la verdadera sistemática del sistema"? (Simon, Josef, El problema del lenguaje en Hegel, traducción de Ana Agud y Rafael de Agapito, Madrid: Taurus, 1982, pp. 191-192).

23 G.W.F., Hegel, Enc, § 250.

24 Derrida, Jaques, op. cit., p. 60.

25 Cf. Hegel, G.W.F., Enc, § 40 I. 
afirma, "es eminentemente propio para ser el eco del alma (...) el modo de expresión más adecuado a la naturaleza del principio espiritual”26.

$Y$ es de suma importancia para nuestra hipótesis el que Hegel entienda esta "adecuación al espíritu" como el rasgo distintivo de la materia sonora, precisamente porque en ella opera "el paso de la espacialidad material a la temporalidad material" 27 . El sonido, sucesivo y no simultáneo, capta la vibración propia de las cosas al desprenderse del espacio y negociar un refugio en la interioridad del tiempo. La temporalidad del sonido ofrece, así, una configuración material tal que es capaz de cobijar al espíritu en su presencia sensible. De ahí que sea el sonido en su versión animada, la voz, el vehículo adecuado para el relevo de la espacialidad de la naturaleza y el ingreso a la temporalidad espiritual, propia del significado. El signo sería, dada su determinación intuitiva última, fundamentalmente fónico. "La voz, articulándose ulteriormente para las representaciones determinadas (...) da a las sensaciones, intuiciones y representaciones una segunda existencia superior a su existencia inmediata; una existencia que vale en el campo del representar" ${ }^{28}$. Y un paso tal, remata Derrida, es precisamente "el momento de la articulación que transforma el ruido en lenguaje" 29 .

Ello, finalmente, explicaría la preeminencia que establece Hegel por parte del lenguaje oral respecto del lenguaje escrito. Este no pertenece al tiempo, sino al espacio: "El lenguaje escrito se extiende por el campo del inmediato intuir espacial del que recoge (§ 454) y produce los signos"30. Que la espacialidad material de las letras no califique dentro del rango espiritual quiere decir que, en virtud de su significado, resulta irrelevante si la letra aparece o no en el espacio: no interesa la forma del trazo, su tamaño, el carácter de la tipografía o las relaciones de coexistencia que establezcan las palabras o las letras sobre

26 Ibid.

27 Ibid., §300. La relación sonido-tiempo es tematizada por Hegel con mayor amplitud en la Estética. Allí, por ejemplo, leemos: "el sonido, en lugar de inmovilizarse y de afectar formas extensas, de ofrecer un cuadro variado de objetos yuxtapuestos y diseminados en el espacio, pertenece al dominio ideal del tiempo, y por consiguiente, en él se borra la distinción de lo interno y de lo externo, de lo invisible y de lo visible, del espíritu y de la materia" (Hegel, G.W.F., Estética, I, traducción de Hermenegildo Giner de los Ríos, Barcelona: Editorial Alta Fulla, p 2I). 28 Ibid., §459.

29 Derrida, Jaques, op. cit., p. 61.

10430 G.W.F. Hegel, op. cit., § 459. 
la superficie. La escritura se limitaría por ello a ser una mera representación secundaria del lenguaje original oral, que es ya de por sí signo; y de ahí que se califique a la escritura elocuentemente como un "signo de signos"3l.

Ahora bien, esta irrelevancia de la apariencia de la escritura sobre el espacio sitúa a los diversos sistemas escriturales en rangos de mayor o menor correspondencia espiritual. Podríamos distinguir entre aquellos sistemas donde la espacialidad de los caracteres es transparente, en la medida en que solo funcionan como signos de sonidos, y aquellos otros donde los caracteres son opacos, pues la espesura misma de su imagen retiene un significado que se resiste a reducirse al rango de mero vehículo de un sonido ulterior.

En el primer modelo (transparente) Hegel identifica al alfabético fonético: aquí las letras eluden su conformación espacial para darle paso al sonido particular que refieren. El espíritu, por decirlo así, vence a la amenaza del espacio echando mano de un sistema en el que el sentido de lo escrito se agota en su ser sustrato de dominio fónico. Aquí la espacialidad de los caracteres se revoca por medio de una constitución tal que los haga permeables a la voz y se garantice, con ello, su subordinación al tiempo. De ahí que no resulte gratuita la afirmación de Hegel según la cual "la escritura alfabética es en sí y de por sí la más inteligente" 32 ."El aprendizaje de la lectura y de la escritura alfabética han de ser considerada como un medio infinito de cultura" ${ }^{33}$. Es importante subrayar a este respecto cómo, en virtud de su temporabilidad y la consecuente elusión de su espaciamiento, este sistema constituye un aliado propicio para el despliegue teleológico de la historia.

En el segundo modelo (opaco), se encuentra más bien el tipo de escritura que Hegel distingue como inferior a la escritura alfabética: la ideográfica o jeroglífica que, a diferencia de esta, "significa representaciones mediante figuras espaciales" ${ }^{4}$. Lo, por decirlo así, peligroso de este sistema es que no niega la espacialidad de sus caracteres sino que la afirma en una suerte de autonomía respecto de la voz. Esta impermeabilidad de los caracteres jeroglíficos en

\begin{tabular}{ll}
\hline 31 & Ibid., § 459. \\
32 & Ibid. \\
33 & Ibid. \\
34 & Ibid.
\end{tabular}


relación a la temporalidad del sonido representaría un escenario de resistencia frente al devenir evolutivo de la historia. Estaríamos, pues, frente a una naturaleza que, liberando al espacio de su subyugación temporal, afirma un tipo inteligibilidad alternativo al discurso espiritual y frena con ello la labor de la dialéctica. No son gratuitos a este respecto los adjetivos con que arremete Hegel en contra de la lengua ideogramática china: además de calificarla de "estática", "imperfecta" y absurda", dice de su lectura que es "sorda" y de su escritura que es "muda" ${ }^{35}$, precisamente los rasgos con los que se habría de describir al lenguaje inadmisible de un espacio autónomo: una negatividad sin garantía de retorno, sorda a los mandatos del espíritu y por eso, en tanto refractaria al tiempo -esa suerte de traductor espiritual-, muda, balbuceante e ininteligible al dictum de la historia.

\subsection{Arte y espacio}

En la introducción de la Estética Hegel define a la belleza como la "apariencia sensible de la idea" ${ }^{36}$. Esta definición nos coloca en terreno, pues en tanto apariencia la belleza se definirá siempre según una articulación particular entre el espacio y el tiempo. Hegel no siempre explicita esta articulación, salvo en una serie de apartados regados a lo largo de sus lecciones donde piensa los materiales sensibles de los que el arte se vale para representar adecuadamente el principio espiritual. Interesa identificar esos pasajes y trazar un recorrido breve por ellos. Se advierte allí la manera en que nuestro autor establece una jerarquía de las artes clasificándolas según criterios espaciales y temporales. El proceso que va del espacio al tiempo es, pues, correlativo al proceso que parte de un inicial apego a la naturaleza (arte simbólico), un progresivo desprendimiento de la misma (arte clásico), para finalmente hallar refugio en la interioridad espiritual (arte romántico). En lo que sigue describiré muy brevemente esta gradación. 
En primer lugar encontramos al arte simbólico, representado por la arquitectura. La relación entre este tipo de arte y la naturaleza como fuente de sus representaciones es la más estrecha dentro de la gradación de las artes. En efecto, el símbolo, dirá, Hegel, "es un signo, pero se distingue de los signos del lenguaje, en cuanto entre la imagen y la idea que representan hay una relación natural, no arbitraria o convencional. Así, el león es el símbolo del valor, el círculo de la eternidad, el triángulo de la Trinidad" ${ }^{37}$. De ahí que sea propio del arte simbólico una lucha incesante entre el contenido espiritual y la forma que nunca encuentra una síntesis adecuada. La naturaleza se halla aquí en contradicción con el espíritu, pues aquella no se llega a comprender lo suficiente como un simple medio de representación del espíritu que la trasciende, sino que pretende significarlo inmediatamente (p. ej.: religión persa de Zoroastro: la luz no es la representación de Dios, es Dios) ${ }^{38}$. Esta tensión hace que el espíritu no encuentre sino a duras penas en la naturaleza un elemento adecuado que le sirva de cobijo. Más adelante, se sugerirá la relevancia del hecho de que Hegel sitúe este tipo de arte específicamente en el Oriente, el espacio de la alteridad por cuanto allí el espíritu no doblega fácilmente la constitución geográfica de la naturaleza y no representa, por tanto, la sede más adecuada para el libre desenvolvimiento de la historia.

Pero por lo pronto corroboremos el sentido que adquiere el que, precisamente allí donde prima lo naturaly en donde el arte adopta su determinación espiritual más pobre, encontramos a la arquitectura, el arte espacial por naturaleza. En cuanto dominio de lo natural, los propósitos de representación espiritual propios del arte se hallan aquíbruscamente sometidos a los condicionamientos que los materiales imponen.

El elemento de representación sensible de la arquitectura es el espacio en sus tres dimensiones, más específicamente, la materia inorgánica, y esta trabaja disponiéndolas según las leyes de la gravedad, articulándolas con regularidad y simetría, de tal forma que se obtenga, en su conjunto, una obra de arte que

37 lbid., p. 114.

38 Cf. ibid., p. 120. 
"ofrezca un simple reflejo del espíritu" 39 . Sin embargo, esta disposición simétrica del espacio no alcanza a constituir una manifestación lo suficientemente adecuada al espíritu, pues la relación que la arquitectura establece con sus materiales no está orientada a la presentación del espíritu en su libertad, sino a propósitos prácticos y utilitarios relacionados con la necesidad de albergue o cobijo. Es elocuente, en ese sentido, que Hegel le atribuya a la arquitectura egipcia (el pueblo arquitecto por excelencia) adjetivos semejantes a los que atribuía a la lengua ideogramática china. La preminencia del espacio obstruye la inteligibilidad de la materia de cara al espíritu: los egipcios "muestran una actividad infatigable para satisfacer esta necesidad de representación simbólica que les atormenta. Pero sus monumentos permanecen misteriosos y mudos; el espíritu no ha encontrado todavía la forma propia, no sabe hablar aún el lenguaje claro e inteligible del espíritu mismo. Es sobre todo un pueblo arquitecto"40.

\section{Escultura (arte clásico)}

En este punto nos desplazamos de Oriente a Occidente hasta pisar terreno griego. El arte escultórico permanece aquí atado a la naturaleza, pero dispone de ella de tal forma que se aproxima en mayor grado que la arquitectura al principio espiritual. En efecto, no se limita a articular simétricamente las tres dimensiones de la materia inorgánica organizándolas según fines prácticos, sino que ahora dispone del espacio, pero para representar una realidad más ideal porque orgánica: la "individualidad espiritual” propia del cuerpo humano. La naturaleza se contrae desde la masa grávida de la materia inorgánica para concentrarse en la particularidad del cuerpo, que es, dentro del conjunto del universo sensible, el que más deja impregnar en su exterior la evidencia de un alma interna. Así, sí desde el lado del contenido representa el calmo y sereno reposo del cuerpo en su unidad inmediata, desde el aspecto de la forma, la materia está vivificada por su especial modulación humana. Forma y contenido hallan aquí, a diferencia de la arquitectura, una adecuación absoluta ${ }^{41}$.

39 Ibid., pp. 293-294.

40 Ibid., p. I27. Las cursivas son nuestras.

$4 I \quad C f$. Hegel, G.W.F., Lecciones de estética, traducción de Alfredo Llanos, Buenos Aires: La Pléyade, 1977, p. 134. Como se podrá ver, en lo que sigue de esta sección, salvo en la nota 43, utilizamos la edición de Alfredo Llanos en lugar de la consultada hasta el momento, a cargo de Hermenegildo Giner. Reconocemos los problemas que conlleva consultar de manera alterna dos ediciones distintas de la misma obra, y nos comprometemos a resolver el impasse en trabajos posteriores. Esta decisión, sin embargo, obedece eventualmente a lo siguiente: encontramos 
Lo que nos interesa resaltar por el momento es que esta remisión de la naturaleza inorgánica a la materia idealizada del cuerpo representa para Hegel el ingreso a la "espacialidad abstracta" y el abandono de la mera espacialidad mecánica de la arquitectura. Esta correspondencia entre el reposo interior del alma y la serenidad externa del cuerpo es, dice Hegel, "la figura en su abstracta espacialidad (...) la escultura se guarda bien de permitir que la forma exterior se extravíe en la variedad de los accidentes y el azar, sino que represente aquel único aspecto, es decir, la espacialidad abstracta en la totalidad de sus dimensiones" 42

\section{Pintura, música y poesía (arte romántico)}

Finalmente, la idea se desplaza en este nivel al estadio de la subjetividad espiritual. Ahora el arte se ocupa de la interioridad, de los sentimientos y de las emociones particulares de la vida del hombre. El arte romántico se definirá, en ese sentido, por una progresiva inadecuación entre el contenido y la forma de representación. La naturaleza material se va purificando paulatinamente asediada por la sombra de su verdadero interés espiritual hasta, finalmente, consumarse como mero medio o signo de la idea. Veamos cómo este desplazamiento corre paralelo a un progresivo desvanecimiento del espacio como elemento de representación para darle lugar al tiempo, en conformidad a su mayor adecuación espiritual.

La pintura, para empezar, idealiza el espacio propio de la escultura pero de manera distinta a como esta lo hacía respecto de la arquitectura. Y lo hace básicamente en dos aspectos: por un lado, "para expresar mejor el alma y sus sentimientos, reduce las tres dimensiones de la extensión a la superficie, siendo esta, aunque material, más cercana al espíritu. Representa el alejamiento de los objetos, su distancia respectiva en el espacio"43. Del otro, subjetiviza la

que la traducción de Llanos es más clara en su vocabulario respecto a la lógica del tránsito entre, por un lado, la espacialidad (visual) operante en la arquitectura, la escultura y la pintura $y$, por el otro, la temporalidad (sonora) que acontecen en la música y en la poesía. A este respecto interesa principalmente el protagonismo que, en la presente traducción, cobra el concepto de punto como elemento mediador entre ambas instancias: el que la superación antes descrita del espacio en el tiempo vía el punto encuentre aquí su correlato estético en el tránsito que va de la luz/color al sonido demarca el límite entre las artes espaciales y las temporales de una manera especialmente sugerente dada la hipótesis de este artículo.

42 Ibid.

43 Hegel, G.W.F., Estética, p. 295. 
"visibilidad concreta" a la que remite el espacio de la arquitectura y la escultura, convirtiéndola en una "visibilidad abstracta"44. Esto significa que si en dichas artes las relaciones de coexistencia y los contrastes se expresaban mediante cierta composición de sus dimensiones espaciales, en la pintura el contraste se expresa inmanentemente mediante los colores, que Hegel define como medios de subjetivación espiritual ${ }^{45}$.

Ahora bien, una subjetivación más profunda deberá "suprimir las coexistencias indiferentes que llenan el espacio y que el color deja aun subsistir, idealizándolas y reuniéndolas en un punto" ${ }^{\prime 4}$. Recordemos para empezar que, según el pasaje citado al comienzo ${ }^{47}$, el tránsito del espacio al tiempo remitía al punto como elemento de mediación. Hegel interpreta ahora esta supresión de la coexistencia espacial al punto como la instancia a través de la cual se dota de movimiento a la materia, tornándola vibrante y otorgándole, de este modo, lugar al sonido ${ }^{48}$. La visibilidad abstracta deviene, así, "audibilidad abstracta"49. En otras palabras, Hegel está describiendo el paso de la pintura a la música echando mano de una lógica análoga a la que operaba en el tránsito del espacio al tiempo. Incluso lo dice explícitamente: "la extensión espacial se transforma en un punto, el punto que se mantiene no es otro que el tiempo. A este elemento corresponde la segunda división del arte romántico: la música" ${ }^{50}$. Abandonamos por fin las artes espaciales y nos situamos en el espectro de las artes temporales, instancia en la que es el sonido temporal y no ya la visibilidad espacial el que funciona como elemento de expresión y el que explica por qué estas artes ocupan el mayor rango espiritual dentro de la gradación de las artes.

Que sea el sonido, el elemento sensible menos apariencial de todos, el que sitúe a estas artes en el mayor rango espiritual, va dando cuenta de la progresiva insuficiencia de la naturaleza respecto de su capacidad para albergar al espíritu y su consecuente reducción como mero vehículo o signo de aquel.

44 Hegel, G.W.F., Lecciones de estética, p. 138.

45 Cf. ibid.

46 Ibid.

47 Véase la página 5 de este artículo.

48 Cf. ibid.

49 lbid.

I $10 \quad 50 \quad$ Ibid, p. 139. 
Esto es precisamente lo que consumaría el arte más espiritual de todos: la poesía. Porque si bien la música utilizaba sonidos, la melodía y el ritmo tenían que ser considerados como fines en sí mismos y no, como en el caso de la poesía, meros signos al servicio de un espíritu libre ya de toda atadura natural: el significado. En efecto, la materia sonora del signo ofrece una factura tal cuya apariencia efímera se abole en el proceso temporal de su significación ideal. Revocando su presencia, dispone así su ingreso a una espiritualización de mayor rango. Por eso la consumación del arte en la poesía coincide con su propia disolución como tal para darle ingreso a la prosa del pensamiento.

Hemos rastreado, así, el proceso por el cual lo que al inicio (arte simbólico) era una relación inadecuada entre la naturaleza y el espíritu, donde la naturaleza era demasiado grávida para que el espíritu se sobreponga a aquella, hacia el final (arte romántico), y pasando por la mediación del arte clásico, donde naturaleza y espíritu alcanzaban adecuación armónica, se trata también de una relación dispar, pero por las razones contrarias: el espíritu se ha liberado por fin de la naturaleza en virtud de la asistencia de un tiempo que ha revocado paulatinamente al espacio natural.

\subsection{Geografía y espacio}

En el segundo capítulo de la Introducción especial de las Lecciones sobre la filosofía de la historia universal, referido a los fundamentos geográficos de la historia, Hegel se propone analizar las relaciones entre el espíritu y la naturaleza, pero echando mano de una lógica opuesta a la manera en que había venido operando en la Introducción general. Si en esta, leíamos: "Aquí no hemos de considerar la naturaleza como constituyendo también por sí misma un sistema de la razón, realizado en un elemento particular característico, sino relativamente al espíritu" 1 . Ahora, en la Introducción especial, leemos: "Lo que hemos de considerar aquí son diferencias naturales (...) de las cuales se desprende el espíritu y de este modo ofrecen la base geográfica. No nos proponemos conocer el suelo como un local externo, sino el tipo natural de la localidad, que corresponde exactamente al tipo y carácter del pueblo, hijo de tal suelo"52.

5I Hegel, G.W.F., LFHU, p. 59. Las cursivas son nuestras.

52 Ibid., p. 162. Las cursivas son nuestras. 
Este segundo pasaje resulta extraño de cara al sistema hegeliano en su conjunto, pues invertiría la preeminencia, esencial en la filosofía de Hegel, del espíritu por sobre la naturaleza. Se busca pensar a la naturaleza no ya como relativa al espíritu, sino, al contrario, al espíritu como relativo a la naturaleza. El espíritu de un pueblo (Volkgeist) es aquí "hijo de tal suelo", de forma que es en cierto modo la naturaleza la que condicionaría la factura espiritual que a cada pueblo le corresponde.

En relación al estudio de la historia, una de las novedades que trae consigo este enfoque es que se tratará no ya de pensar a los pueblos como una forma "individual en la que el espíritu se representa a sí mismo" ${ }^{33}$, sino como realidades concretas y existentes, inscritas al interior de un espacio y un tiempo determinados y adquiriendo todas las características de un "individuo natural que como tal, florece, decae y muere" 54 . "Los pueblos, como formas espirituales, son también seres naturales en cierto sentido. Por esto los distintos productos se presentan también coexistiendo y perdurando en el espacio, indiferentes unos a otros" 55 .

Ahora bien, el principal problema a que conduce este enfoque es que la tesis según la cual el espíritu ha resultado "hijo de un suelo" y, por lo tanto, relativo y condicionado por la naturaleza, entraría en contradicción con la clave de la tesis hegeliana según la cual "la sustancia del espíritu es la libertad"56. En efecto, si el espíritu de los pueblos se halla condicionado por el suelo natural de donde brota, la hipótesis de la absoluta autonomía del espíritu por sobre la alteridad de la naturaleza se halla por lo menos en una situación incómoda. Esta dificultad ha llevado a autores como Jaques D' Hondt a interpretar, nos parece, de manera errónea la intención del presente capítulo. Para D' Hondt, este extraño capitulo representaría una "tenaz desmentida a la tesis de la autonomía absoluta del espíritu (...). Este concepto se opone al idealismo absoluto comprendido esquemáticamente" 57 . "Un poco de sustancia

53 lbid., p. 65.

54 lbid., p. 161.

55 lbid., pp. |30-13।.

56 lbid., p. 68.

57 D’Hondt, Jaques, Hegel, filósofo de la historia viviente, Buenos Aires: Amorrortu, 1966, p. 
-afirma- quedaría fuera del sujeto" ${ }^{58}$, queriendo ver en ello el papel que a su juicio ejerce el azar en el devenir de la historia. Nosotros discrepamos con D' Hondt en este punto y vamos a explicar por qué.

Pensamos que el problema de la interpretación de D'Hondt consiste en que no advierte lo suficiente la singular relación que Hegel establece entre el espacio y el tiempo en que los pueblos aparecen como determinaciones naturales, relación cuya trama, tal como hemos venido mostrando a lo largo de este trabajo, inocula en la naturaleza las propias condiciones de su revocación.

Recordemos que cuando Hegel define a la naturaleza desde la filosofía de la naturaleza desarrollada en la Enciclopedia, ésta aparece como espacio y tiempo. Pero cuando lo hace desde las Lecciones sobre la filosofía de la historia universal, que en el sistema de la Enciclopedia correspondería a la filosofía del espíritu, relega al espacio a la naturaleza y escinde el tiempo de la naturaleza para colocarlo también del lado del espíritu. Todo consiste, pues, en la escisión del tiempo en dos frentes: tiempo natural y tiempo histórico. Ahora bien, dado que en este momento nos encontramos al interior de la Filosofía del espíritu, hay que leer la tesis geográfica a la luz de dicha escisión. Desde esta perspectiva, no es la factura natural de un pueblo la que determina su configuración espiritual, sino la que permite distinguir su posición y rango al interior de la trama de la historia. Se diría que dicho rango se establece de acuerdo al grado de inteligibilidad que ofrece el espacio de un pueblo de cara a las condiciones que hacen posible su inserción al interior del tiempo histórico. Así, la tesis geográfica de Hegel no desmentiría la tesis de la libertad absoluta del espíritu, sino que más bien pondría en evidencia la estrategia singular con que opera un principio de selección y exclusión de los pueblos como sedes más o menos aptas para servir de sede al desarrollo de la historia universal.

Quizá la definición que del concepto de lugar ofrece La Enciclopedia esclarezca la operatividad de esta estrategia: "El lugar es la singularidad espacial y, por ello, la singularidad indiferente; $y$ esto lo es el lugar solamente en cuanto ahora espacial, ósea en cuanto tiempo" 59 . La cita resulta útil porque da luces acerca de la lógica a través de la cual los espacios son excluidos o incorporados, según 
sea el caso, en la trama de la historia dada su constitución geográfica. Muy a grandes rasgos: si, de acuerdo a la cita, el lugar describe la consumación del espacio como tiempo, y el tiempo es precisamente el enlace entre la naturaleza y el espíritu, entonces podemos concluir que solo merecen un lugar en la historia universal aquellos espacios que, al no ofrecer su constitución natural una resistencia lo suficientemente poderosa, se han dejado absorber (casi, diríamos, colonizar) por el tiempo histórico. El lugar resulta, así, propiamente, un espacio historificado. La historia universal no sería la historia de los espacios, sino la de los lugares propiamente dichos. llustremos, para terminar, esta lógica repasando la constitución natural que han de tener, a juicio de Hegel, los lugares que representan escenarios adecuados para el desarrollo de la historia.

Hegel describe estos escenarios según una relación particular que al interior de cada pueblo se establece entre el agua y la tierra. Tres son los paisajes bajo los que se presenta esta relación: las mesetas, los valles y los litorales. Las mesetas se caracterizan por sus llanuras exentas de agua suficiente para hacer del suelo permanente terreno de cultivo. Por eso este tipo de pueblos, nómadas en su mayoría y propios de algunas zonas de África y América, no están atados a ninguna zona específica y es en virtud de esta "ilimitación abstracta" que carecen del espíritu de la inquietud requerida para que el espíritu florezca ${ }^{60}$. Esos pueblos no encuentran, por ello, un lugar en la historia universal. Los valles, por su parte, son el paisaje propio del Oriente y están formados por grandes corrientes de agua, lo que permite la aparición de terrenos fértiles y el consecuente tránsito a la agricultura. La agricultura implica "la cesación de la inestabilidad (...) y exige cuidados y preocupaciones por el futuro, lo cual despierta la reflexión sobre algo universal"61. Ella es, por tanto, el suelo más propicio para el nacimiento de la cultura y la historia ${ }^{62}$. La historia nace en Oriente. Sin embargo, al estar cercado el valle por un cinturón de montañas ha obligado a sus pueblos a permanecer "encerrados dentro de sí mismos"63 e inhibe la voluntad y necesidad de trascendencia. El espíritu se traslada entonces

60 Cf. Hegel, G.W.F., LFHU, pp. 165-166.

61 lbid., p. 197.

62 Cf. ibid.

I|4 63 Ibid. 
al Occidente, allí donde, a juzgar de Hegel, "la humanidad es más libre por cuanto no hay ningún principio natural que se imponga como dominante"64.

De esta forma, la verdadera sede de la Historia universal la encontramos en el mediterráneo, escenario del hombre europeo. Aquí entran en contacto el agua con la tierra, lo cual arranca al hombre del círculo limitado del valle, que "fija al hombre al terruño" 65 , para enfrentarlo a esta animación a lo ilimitado que el espectáculo del mar ofrece. Y así como la meseta era el reino de la pura contingencia en medio de la llanura indistinta, y el valle el repliegue hacia la firme limitación, el mediterráneo representa la síntesis de ambos polos, pues contempla tanto la gravidez de la tierra como la contingencia y fluidez del mar.

\section{$\S$ 4. Reflexiones finales}

I. El interés por el tratamiento del concepto de espacio en la filosofía de Hegel aparece mejor perfilado una vez que advertimos su encuadre al interior de una metafísica y de una teleología de la historia. Es desde esta perspectiva que la preeminencia categorial del tiempo por sobre el espacio, si bien resulta una constante en la historia de la metafísica de Platón en adelante, exige aquí, sin embargo, una atención especial. La clave consiste en atender al modo en que esta preeminencia está orientada a legitimar conceptualmente la superioridad de ciertas formas espirituales por sobre otras, derivando en última instancia en una especie geopolítica de la historia. El propósito de este trabajo no ha consistido en desarrollar este punto, pero su preocupación de fondo persigue el interés de utilizar la presente exposición como premisa para una tematización más a fondo sobre este problema en futuras investigaciones.

2. La relación entre metafísica de la historia y geopolítica queda bien ilustrada en la tesis según la cual la historia, como el sol, describe un movimiento evolutivo que va de Oriente a Occidente ${ }^{66}$, y no alumbra en su recorrido territorios como los de África y América. Tanto el tratamiento del lenguaje, como el del arte y la geografía recaen al interior

64 lbid., p. 199.

65 Ibid., p. 197.

66 G.W.F., Hegel, LFHU, op cit., p. 201. 
de este principio, que bien podríamos aventurarnos en calificar como un principio topológico. En los tres escenarios asistimos a una suerte de topología de las determinaciones espirituales. El signo oral y escritural, en el caso del lenguaje, los géneros, en el caso de las artes, y los territorios, en el caso de la geografía, traducen su mayor o menor grado de inteligibilidad en un determinado emplazamiento al interior de la gran sede de la historia, sin contar el hecho de que, en el peor de los casos, algunas configuraciones no alcanzan siquiera sede alguna.

3. Esto cobra sentido si distinguimos por lo menos dos niveles o roles que la naturaleza desempeña en este proceso de formación. Por un lado, la naturaleza es la materia inmediata y, por lo tanto, abstracta, del trabajo espiritual. Digamos, espacio como pura alteridad indistinta. Por el otro, la naturaleza es la materia mediada que ha retornado desde la exterioridad a la interioridad del espíritu: espacio temporalizado, inteligible, subsumido a la identidad por obra de la fuerza negativa del tiempo. Pues bien, es en este segundo nivel en donde los grados de inteligibilidad de las formaciones espirituales aparecen como emplazamientos históricos y en donde la metafísica de la historia se organiza espacialmente como geopolítica. Allí tenemos, pues, a la inferioridad del ideograma espacial chino respecto del alfabeto fonético del mediterráneo dada la permeabilidad del último a la temporalidad del sonido. También, al arte simbólico de la arquitectura egipcia como inferior al arte clásico de la escultura griega, y a la superioridad de la pintura (artes espaciales), la música y la poesía del arte romántico germánico (artes temporales), haciendo pasar una gradación cualitativa en un trayecto espacial de oriente a occidente. Y, por último, al principio de exclusión de los pueblos que desde el punto de vista geográfico selecciona y discrimina territorios de acuerdo al tipo de factura natural y a la permeabilidad de la misma en relación al dominio que el espíritu sea capaz de ejercer sobre ella.

Ahora bien, es claro según lo anterior que el interés por la exploración del problema del espacio en Hegel no va de la mano con la suscripción del contenido de las tesis que el filósofo subraya. Pero la dialéctica tiene la virtud de sobrevivir como aparato crítico aun cuando se le utilice para pensar más acá de la filosofía hegeliana e, incluso, en orden a desmontar los presupuestos que legitiman la teleología de la historia que está en su base. Hemos visto cómo I I 6 dicha teleología depende del diseño de un concepto de tiempo que funciona, 
a la vez que como negatividad, como aplacador de esta misma negatividad, es decir, como garantía de retorno y reconciliación de lo otro a la identidad consumada del espíritu. En este sentido, la apuesta por pensar el espacio, no ya al servicio de la identidad del espíritu, sino, digamos, desde el estrés de su propia inmanencia, iría de la mano con el esfuerzo por pensar lo otro de la historia, aquello que se resiste a ser reabsorbido por la identidad del concepto, generando canales de inteligibilidad alternativos a la hegemonía del discurso del progreso y de la historia oficial. Desde esta perspectiva, sería posible hablar no solo de un pensamiento del espacio sino además de una suerte de espacialidad del pensamiento, entendiendo por ello aquel gesto de desmontaje y reconducción de la operatividad del discurso al plano de sus condiciones de posibilidad y producción de sus estrategias de autolegitimación. Si bien, insisto, esta brecha abre la investigación más allá de los alcances de este artículo, la relación entre espacio y crítica exhibe, en este sentido, una vía de reflexión que valdría la pena explorar. 